\title{
Culture Shock: Literature Review, Personal Statement and Relevance for the South Pacific
}

\author{
Adrian Furnham \\ University College London, United Kingdom
}

\begin{abstract}
This his article considers the popular concept of culture shock from three perspectives. The first is from the academic perspective, considering how researchers from different disciplines (anthropology, education, psychiatry, psychology, sociology) attempted to operationalise the concept and understand the process behind it. It represents 50 years of research using different methodologies and trying to answer different questions about the experience of travel for many reasons. This section of the article also considers issues concerned with the 'overseas' student; of which there are ever more travelling abroad to study. They can have serious culture shock difficulties. This is followed by a short section on migration in the South Pacific and the consequences for large and small countries, particularly that of sojourning, migration and refugees. The final section is a personal statement and reflection on culture shock and how I came to write two books and around a dozen papers on the topic.
\end{abstract}

Keywords: culture shock, foreign students, migration, travel, sojourn

There is, as one may expect, some dispute and debate as to who conceived the concept of culture shock and precisely when this occurred. There is less debate about its definition and psychological consequences. Over the years various researchers have tried to refine the definition of the term looking at very specific psychological factors or facets that make up the experience (Winkelman, 2003; Xia, 2009). It has been seen as a loss of one's culture, a marker of moving from one culture to another, and as a resocialisation in another culture. It comes as a 'hurtful surprise' to many who travel for various reasons.

There remains no clear definition of culture shock, usually attributed to the anthropologist, Oberg (1960) over 50 years ago. Various attempts have been made to 'unpack' the definition (Ward et al. 2001):

1. Strain due to the effort required to make necessary psychological adaptations.

2. A sense of loss and feelings of deprivation in regard to friends, status, profession and possessions.

3. Being rejected by/and or rejecting members of the new culture.
4. Confusion in role, role expectations, values.

5. Surprise, anxiety, even disgust and indignation after becoming aware of cultural differences.

6. Feelings of impotence due to not being able to cope with the new environment.

While the term 'culture shock' may have originated in the academic literature it very quickly took root in the popular imagination. The popular media has been full of references to culture shock for 50 years. Guides on how to mitigate the effects of culture shock are offered to all sorts of travellers. People recognise it immediately though they are surprised by it. There are many related definitions but they nearly all convey a similar meaning. The concepts quoted are: 'disorientation', 'anxious confusion', 'disease' or 'mental shock' or 'transition shock': it is agreed that culture shock is a disorientating experience of suddenly finding that the perspectives, behaviours and experience of an individual or group, or whole society are not shared by others. However, it is also agreed that it is a ubiquitous and a normal stage in any acculturative adaptive process that all 'travellers' experience. Going to 'strange places' and losing the power of 
easy communication can disrupt self-identity, world views and indeed all systems of acting, feeling and thinking.

There are long lists of the symptoms of culture shock that include cognitive, emotional, physiological and other reactions. Some researchers have attempted to specify personal factors that seem to predict who and how much individuals suffer from culture shock like openness, neuroticism, language proficiency and tolerance for contradiction (Spencer-Rodgers, Williams, \& Peng, 2010).

There are many rich personal accounts and helpful advice procedures for people to develop better 'emotional resilience' to move between cultures (Abarbanel, 2009; Azeez et al., 2004; Barrett, 2009; Bourne, 2009; Green, 2006). This includes what people in educational and work environments can and should do to lessen the experience of culture shock (Guy \& Patton, 1996).

Culture shock has been studied in many groups including tourists (Court \& King, 1979); students (Gaw, 2000; Sayers \& Franklin, 2008, Willis, 2009; Xiaoqiong, 2008) and working people (Guy \& Patton, 1996). The costs of expatriate failure have encouraged researchers to try and understand causes, as well as reduce the amount of culture shock that results (Pires, Stanton, \& Ostenfeld, 2006).

Some researchers have developed and tested simple models to try to predict who suffers most from culture shock (Kaye \& Taylor, 1997). Shupe (2007) proposed a model to understand international student conflict. However, the most sophisticated model has been proposed by Zhou, Jondal-Snape, Topping and Todman (2008). They suggested that there are essentially three contemporary theories in the area: Stress and Coping (cross-culturally travellers need to develop coping strategies to deal with stress because life changes are inherently stressful); Culture Learning (cross-cultural travellers need to learn culturally relevant social skills to survive and thrive in their new settings); and Social Identification (cross-cultural transition may involve changes in cultural identity and intergroup relations). They propose that there are both individual level (person and situation factors) and societal level variables (society of origin and society of settlement) that jointly determine stress and skills deficit that in turn determines stress coping and skills acquisition. Following this, they noted how culture differences in learning practices and procedures leads to mismatching, misunderstanding and misery as students go abroad to further their education.

People have, and will always, travel to 'far off lands', different countries and regions for very different purposes. To convert and then conquer, to trade and to teach to learn and to settle. There are many ways to categorise these travellers, that is, how long they go for (i.e., migrants vs. sojourners vs. tourists); how far they travel (near vs. far); their motives for movement (education, trade, expansion); the nature of stranger-host relations (friendly vs. antagonistic). There are many types of sojourners: business people, diplomats, the armed forces, students, voluntary and aid workers, missionaries, and so on, who often spend 6 months to over 5 years in 'other countries' in order to do business, represent their country, protect others or instruct other armed forces, study, teach or advise locals, convert and proselytize, respectively. It is obviously important that these sojourners adapt to the new culture rapidly in order that they may operate effectively in whatever they are doing. The costs of repatriation and breakdown are high. This article considers the studies on foreign students and their experiences of culture shocking.

There are few psychometric tools specifically trying to measure culture shock. Rudmin (2009) reviewed various measures of acculturation and acculturative stress of which there are a number. However, Mumford (1998) devised and validated a short 12-item measure divided into Core items and Interpersonal stress items.

Culture shock is conceived as a serious, acute and sometimes chronic affective reaction to a new (social) environment. However there are other closely related 'shocking' experiences. These includes:

- Invasion shock: this occurs in places where tourists or other visitors suddenly appear in large numbers in a particular setting and overwhelm the locals who become a minority in their own living space. Because the 'invaders' retain their cultural morals (of dress, social interaction) they can surprise, frustrate and offend the locals. In this sense they have culture shock without actually going anywhere. Pyvis and Chapman (2005) noted how home students can feel culture shock in their home country but at an institution that accepted many overseas students.

- Reverse culture shock: this occurs when returning to one's home culture to find it different from that which was recalled. In this sense, you can never go home again because it does not exist. It is about readjusting, reacculturating and reassimilating in the home culture (Gaw, 2000).

- Re-professionalisation and re-licensing shock: this occurs when trained professionals do not have their qualifications accepted by a host country and have to be retrained and accepted (Austin, 2007; Austin, Gregory, \& Martin, 2007).

- Business shock: this is the realisation that so many of the subtle business practices vary considerably from one culture to the next (Balls, 2005; Pukthuanthong \& Walker, 2007).

- Race culture shock: This concerns being a racial minority in an instution within ones country. Class and race specific styles of dress, speech etc can seriously shock people who do not expect them (Torres, 2009). 


\section{Foreign Students, the Educational Sojourn and Culture Shock}

Although the practice of students travelling from one country to another has been established for centuries, particularly in Europe, it is not until comparatively recently that they have become the focus of study (Ward, Bochner, \& Furnham, 2001; Miller \& El-Aidi, 2008). In 1902 in Great Britain the Colonial Office appointed a Director of Colonial Students. An early study in America, published in 1925, listed the seven major problems of foreign students as being academic/curriculum issues, language problems, economic issues, housing difficulties, their inability to become socially accepted, difficulties in health and recreation and racial prejudice (Hammer, 1992). There are various books exclusively on foreign students that look at the psychology of their experience. (McNamara \& Harris, 1999; van Tilburg Vingerhoets, 1997).

Culture-learning and its effects on the ethnic identity of foreign students remain the concerns along with gender issues, staff-student relationships and learning preferences, and styles of different groups. There is also an increasing interest in the social networks of foreign students, both while on sojourn and after returning home. Studies have also looked at the cross-national networks that some of these individuals join as a result of having studied abroad and at the mediating function that these individuals and their networks fulfil in bridging the various cultures to which they have been exposed. Many of the studies now employ a longitudinal design.

Students tend to be young (e.g., twenties), well educated, highly motivated, adaptable, and better off than many of their peers. Much of this research suggests that many students feel classic alienation especially feelings of powerlessness, meaningless, and social estrangement while being surrounded by the 'superficial pleasantries' of their hosts. Most of the research studies have been aimed at looking at the affective, behavioural and cognitive consequences of cross cultural transition in sojourners and have attempted to establish which individual, interpersonal, social, structural and economic factors best predict adjustment.

Foreign students face four sorts of problems, two of which are exclusive to them (as opposed to native students). First, there are the problems that confront anybody living in a foreign culture, such as racial discrimination, language problems, accommodation difficulties, separation reactions, dietary restrictions, financial stress, misunderstandings and loneliness. Second, there are the difficulties that face all late adolescents and young adults, whether they are studying at home or abroad, in becoming emotionally independent, self-supporting, productive and a responsible member of society. Third, there are academic stresses when students are expected to work very hard, often under poor condi- tions, with complex material. Fourth, the national or ethnic role of overseas students is often prominent in their interactions with host members

\section{Student Exchanges}

Some of the earliest studies concerned the suicide of university students (Gunn, 1979). The assumption that the experience of relocating to, and living in another country is usually stressful for young people, is being challenged. By the mid-1990s there was a sizeable literature on the psychological needs and problems of international students. Sandhu (1994) in a review categorised the main cause of problems as intrapersonal factors: a profound sense of loss (family and friends), a sense of inferiority (particularly in America), a sense of uncertainty (about the future); and interpersonal factors: communications problems (language and social skills), cultural shock (differences in expectations and social norms), loss of social support systems (particularly from family), miscellaneous factors such as education and immigration difficulties, and the nature of the problems that the students face such as homesickness, fear, guilt and discrimination.

What are the implications for helping foreign students? First, that counselling should be proactive, not reactive, and seek out international students who may be vulnerable. Second, guidance services should be continuous and comprehensive, not simply confined to orientation sessions soon after arrival. Third, that alternative, less stigmatised approaches should be available through less formal and clinical contacts, such as interest or friendship groups. Fourth, students should be encouraged to become involved in their own adaptation process as well as the education process as a whole. Fifth, the idea of the buddy system, so long used in the American army, should be established. Sixth, students could be encouraged to feel a certain amount of empowerment through communication workshops set up for them. Seventh, counsellors should be sensitive and trained in culture differences, specifically the presentation of psychological problems. Indeed, there are so many orientation programs now available at universities that there is an active research program in measuring their efficacy (McKinlay et al., 1996).

\section{Students' Health}

One of the most influential papers in this area was that of Ward (1967), who argued for the existence of a 'foreign-student syndrome', which is characterised by vague, nonspecific physical complaints: a passive, withdrawn interaction style and a dishevelled, unkempt appearance. His thesis, which was to influence a lot of subsequent work, was that depressed and 'cultureshocked' overseas students tend to somatise their problems so as to avoid losing face, thus providing them with the justification to attend clinics for medical, as opposed 
to psychological help. Hence it is to be expected that foreign students would be over-represented in student health services.

Studies purporting to show differences in the mental health of native and overseas students by using medical consultation rates must be interpreted with caution. Overseas students may have no other source of help, and their beliefs about the causes and treatment of illness may differ from those prevalent in the host country. Also an above-average consulting rate for any group (native or foreign) may arise from very frequent visits from a small subgroup of its members prone to visiting doctors. Hence the average number of visits per individual has to be considered, and if the distribution is badly skewed, appropriate corrective statistics used.

It is perhaps no surprise that educational institutions have established orientation and counselling programs for their international students. Some studies have reported incidence of fairly severe breakdown. For instance, Janca and Hetzer (1992) in a 25 -year retrospective analysis of the psychiatric morbidity of foreign students in Yugoslavia, traced 63 foreign and 120 domestic students who were hospitalised, and found high rates of paranoia and depressive reactions. Of the foreign students admitted, $67 \%$ showed paranoid delusions, $62 \%$ anxiety, and $52 \%$ anxiety which they took as evidence of the correlational between 'psychiatric morbidity and maladaptation to the new living conditions' (p. 287).

\section{Student Friendship}

One area of research that is theoretically important is the work on foreign student friendship networks. Bochner and his co-workers (Bochner, McLeod, \& Lin, 1977; Furnham \& Bochner, 1986) have shown some interesting trends in the friendship networks of overseas students. In a study of foreign students in Hawaii, Bochner et al. (1977) developed a functional model of overseas students' friendship patterns, stating that the sojourners belong to three distinct social networks. These are: A primary, monocultural network consisting of close friendships with other sojourning compatriots. The main function of the co-national network is to provide a setting in which ethnic and cultural values can be rehearsed and expressed. A secondary, bicultural network, consisting of bonds between sojourners and significant host nationals such as academics, students, advisors and government officials. The main function of this network is to facilitate instrumentally the academic and professional aspirations of the sojourner. A third, multicultural network of friends and acquaintances. The main function of this network is to provide companionship for recreational, 'non-cultural' and non-task-orientated activities.

Many argue that the amount of social support, rather than who provides it, is more important. Thus Pantelidou and Craig (2006) found the quality of social support significantly reduced culture shock in Greek migrant students. Others, however, place more emphasis on the source of support and its functions of social support. Thus help from a host-national network is important because through it foreign students can learn the social skills of their culture of sojourn. Help from the co-national network is important because through it foreign students can maintain their culture of origin. The theory predicts that the wellbeing of foreign students depends on them having access to both types of networks. However, the evidence suggests that most foreign students do not belong to a viable host-national network.

\section{Sojourner Homesickness}

As noted in the previous chapter the topic of homesickness has attracted renewed theoretical and empirical attention. Hannigan (1999) in a review of the salient literature identified various factors associated with homesickness. They are:

- Language proficiency: Inability to speak the host language inevitably isolates the student, making them excessively dependent on compatriots.

- Employment: In some countries nearly all students have part-time jobs that provide them with money, time structures and useful contacts in the world of work. The idea that part-time work is important as a source of self-respect and as an important opportunity for culture learning seems to have been seriously neglected in the previous literature.

- Self-identity: All researchers have observed that overseas study often occurs at a critical period in the life cycle of young people, notably establishing their personal identity. This process is helped by friends and family in the home culture but if this support is not there, not only does homesickness increase, but difficulties in establishing a clear sense of self and self-worth may remain problem areas.

- Social bonds: Drawing on ideas from attachment theory, it is possible that individual factors concerned with trust and integration, relate to the homesickness patterns in foreign students. Gender roles, skin colour, diet and religious observance all relate to how easy it is for foreign students to integrate into the local community.

- Stress: Often the stress, and consequent homesickness that foreign students experience is a function of realistic expectations of the educational sojourn, trait emotionality, flexibility/tolerance of ambiguity and religious commitment.

However, it may be naive to assume that homesickness can be easily treated. Van Heck et al. (1997) showed that homesickness is systematically related to personality variables. Predictably introverted, neurotic students who are relatively closed to new experiences seem especially 
vulnerable to homesickness. Students with low selfesteem, poor social skills and those prone to both rigidity and submissiveness seem particularly vulnerable to homesickness.

\section{Student Adaptation Over Time}

Oberg (1960) was one of the first to describe stages of cross-cultural transition in his discussion of 'culture shock. Since then, a number of authors have proposed stage theories of crossing cultures, the most popular being the $\mathrm{U}$-curve hypothesis and its extension, the $\mathrm{W}$ curve. In its simpler form this refers to a pattern of psychological euphoria, crisis and eventual sojourner adjustment to a new culture and then crisis and readjustment on re-entry. As sound theoretical basis for the U-curve is lacking, and empirical evidence is weak and over generalised (Church, 1982). Further, some recent research has suggested that many students experience feeling adrift depressed and lonely right from the beginning of their stay (Brown \& Holloway, 2008).

Influenced by Bochner et al.'s work on culture learning and more recent theory and research on stress and coping Ward and colleagues set out to investigate the adaptation of Japanese students in New Zealand (Ward, Okura, Kennedy, \& Kojima, 1998). First, they distinguished sociocultural adaptation (the acquisition of culture-specific required to function effectively on a dayto-day basis) from psychological adjustment (emotional wellbeing and satisfaction). Next they predicted and found that the pattern of sociocultural adjustment roughly approximated a learning curve. Contrary to the $\mathrm{U}$-curve proposition but in line with the literature on life changes, they also predicted and found that psychological adjustment was lowest on entry. The advantage of the social psychological model of temporal adjustment is that it can predict and explain different 'adjustment' profiles as a function of quite specific determinants.

\section{Conclusion}

Various patterns in the literature have begun to emerge. For instance, in many cases foreign students do appear to experience more physical and mental ill-health as well as more academic problems than native students. Although there no grand theories attempting to explain this phenomenon, various concepts have been put forward to predict the quality, quantity and chronicity of sojourner distress. One such concept is the culture-distance concept, which states simply that the absolute amount of difference or distance (defined both objectively and subjectively) between a sojourner's own and the host culture is directly proportionally related to the amount of stress or difficulty experienced. Another concept relates to social support and has been described as the functional friendship model which suggests that various friendship networks (host, bicultural and multi- cultural) serve important psychological functions, which in turn help a sojourner over numerous difficulties.

Once again, studies highlighted both intra- and inter-individual factors that related to sojourner adjustment. Psychological research into sojourner adjustment is comparatively new. Large-scale, multifactorial, longitudinal studies which are theory-derived may help considerably to identify the problems of increasing numbers of sojourners the world over.

\section{Movement in the South Pacific}

Getting reliable, comparable and up-to-date migrations statistics on or from any country is problematic. Countries spend different amounts of effort collecting and disseminating this data. But what we do know is that over the past 50 years there has been a great increase in the number of people moving around the world particularly foreign students, migrants and refugees. Population increases by natural increase (births minus deaths) as well as net migration (migrants vs. emigrants). There is also interstate or regional migration.

Thus we know that at the millennium just under a quarter of the population of Australia was foreign born. In all, 25\% came from the United Kingdom, 9\% from New Zealand, 5\% from Italy, $4 \%$ from Vietnam and $3.5 \%$ from China. Over the last few years statistics from Australia have indicated that two thirds of migrants were aged between 15 and 34 years. Further there were over 100,000 foreign students on temporary visas.

The data from New Zealand is equally interesting. It is a country of exchange in that more people emigrate then immigrate, though it is not certain to what extent people return.

The South Pacific may not be very different from any other region. People move, by and large, from poorer to richer countries because of both 'Push and Pull' factors. They move in search of education and employment. They move in search of a better life for themselves and their families. Some countries seem to be dramatic exporters of their population, like the Philippines while often others like Australia seem net importers of people.

Certainly it is a region that is likely to see a great deal of culture shock in a great many people. Some countries lose people: China, India, Korea while others gain them like Australia, Canada, New Zealand, the United Kingdom and the United States.

Some countries seem to use their citizens as a major source of income. For instance it is estimated that over a million Filipinos work abroad roughly half as permanent and half as temporary workers.

It is predicted that the next 50 years will see a great movement of economic and political power from the West to the East. This may mean countries like Australia and New Zealand will 'turn' east rather than west and see their predominant culture changed. It may also see different patterns of migration with far fewer people 
coming from 'old Europe' and far more from 'new Asia'. This can mean social change, even upheaval, as well as many experiencing profound culture shock.

\section{Personal Statement}

Two events accounted for my interest in the topic of culture shock. The first was personal, the second academic. I grew up a member of a double minority - an English-speaking, white South African of immigrant parents who longed, like many migrants, to 'go home' one day. The town I was born in had a majority Indian population, followed by Zulus. It was in a province named by Portuguese explorers. It was where my mother nursed. It had had Norwegian and German migrants in the 19th century. A cultural mix indeed.

Within 200 yards of our house was a small mosque where the cries through the loudspeaker caused consternation. I grew up through the highpoint years of apartheid in a country of great diversity, but one where skin colour and culture dictated every aspect of your life. It was, what statisticians may call, a 'split-plot' design. People from different cultural, racial and ethnic groups were kept apart. 'Separate development' as it was called, tried paradoxically, to ensure there was little culture shock through the mixing and interaction between cultures, but of course it failed. It was in effect a sort of culture dominance or hegemony where old-fashioned Western Puritan Colonist culture imposed its ideas and ideals on all other local native peoples.

My family was not rich and I only left the country of my birth a few times to visit neighbouring countries: Lesotho, Mozambique, and Swaziland with student friends. However, at the age of 22 years I emigrated to England. I was a 'draft dodger', having been called up by the South African Defence force that had conscription to fight Cubans in Angola. Because my parents were British I was a British citizen and had a British passport. I thought of myself as British as my parents had taught me to do so. My father regularly quoted Cecil John Rhodes who supposedly said: 'Remember my boy that you are an Englishman and have consequently won the first prize in the lottery of life'.

I had been brought up on everything English by English parents and therefore expected to find everything totally familiar. It was not. England was smaller, dirtier and more inward looking than I imagined. I was surprised by the class divide and peoples general reluctance to acknowledge it. I was surprised by their hostility to me knowing that I was a white South African. I was, it seemed, expected to take the whole burden of the monstrous apartheid system on my shoulders. I was guilty of the sins of those that ran the country.

I studied at the LSE living in International Hall and befriended many foreign students. People treated me like a foreigner and I occasionally felt like one. As a result, I have always been drawn to foreign students and their particular experiences. I did not expect to feel culture shock at all and I did. But, I have to admit, not for long. I used to watch television programs made for children (especially Blue Peter) to get a idea of how people are socialised in this country.

Over the past decade or so I have travelled extensively. Usually I visit 10 to 20 countries a year to consult, lecture and train. I believe that it is only when working in a country that you begin to understand it. I still experience symptoms of culture shock, particularly in strong homogenous cultures like Japan. I was recently rather disoriented in Uganda where I am an external examiner to Makerere University.

I am sure I always will experience all those emotions and thoughts associated with culture shock. However, now I think I realise where these experiences come from and what to do about it. There are many paradoxes of the whole culture shock experience. Foremost I believe that you learn more about yourself and your values, perceptions and outlooks than the people you come into contact with. In short, 'What know you of England, who only England know?'

The second reason for my interest in the topic was the product of pure serendipity. While completing my $\mathrm{PhD}$ in Oxford I attended a compulsory Friday seminar. It was given by Professor Raymond Cochrane from the University of Birmingham and was about mental health and migration. He was a pioneer in the area and showed that the different migrant groups adapted very differently to their migrant country. Some groups were grossly over represented in prisons and mental hospitals while others were over represented among the rich, entrepreneurial class. The question was why.

I immediately sought and read his papers. Very soon I had traced this literature that crossed disciplinary boundaries. There were papers in anthropology and psychiatry journals as well as in smaller fields like tourism management and migration studies. I began to collect them, read them and ponder over their complex and incongruous findings.

At this time Stephen Bochner, a cross-cultural psychologist from Australia was spending a year in the department. He had spent time in the East-West centre in Hawaii and was most interested in this issue. We talked a lot and decided to write a book. I visited Australia for 6 weeks and wrote part of the book there.

In 1986 a book, Culture Shock, was published. It was a great success being reprinted in 1989, 1990, 1994 and 1999. To date it has been cited over 700 times in academic publications and is my most cited work. But after a decade or so the book needed updating and revising. We were found by a third author, Colleen Ward, an expert on intercultural contact and it problems So we had a South African living in England, a Czech living in Australia and an American living in New Zealand. The 
Psychology of Culture Shock appeared in 2001 and was very well received.

I think the success of these books and our approach is that we have all tried three things. First, to provide some theoretical framework through which to understand this phenomenon. Second, to read widely and to include the salient literature from many disciplines. Third, to look at the practical implications of this work trying to understand what it means to be a foreign student, a migrant or a refugee and how they can be helped.

I remain what the Germans call a 'wandervogal' an albatross happy to wander around the globe. Travel broadens the mind, and the behind, but is exhilarating and thrilling. And I try to keep up with the literature perhaps one day to write a third edition of the book.

\section{References}

Abarbanel, J. (2009). Moving with emotional resilience between and within cultures. Intercultural Education, 20, S133-141.

Austin, Z. (2007). Geographical migration, psychological adjustment, and re-formation of professional identity: the double culture shock experience of international pharmacy graduates in Ontario (Canada). Globalisation, Societies and Education, 5(2), 239-255.

Austin, Z., Gregory, P., \& Martin, C. (2007). Negotiation of interprofessional culture shock: The experiences of pharmacists who become physicians. Journal of Interprofessional Care, 21(1), 83-93.

Azeez, B., Kerne, A., Southern, J., Summerfield, B., Aholu, I., \& Sharmin, E. (2004). Sharing culture shock through a collection of experiences. Retrieved November 1, 2010 from Joint Conference on Digital Libraries.

Balls, A. (2005). Business culture shock. Retrieved November 1, 2010, from http://www.highbeam.com/NZ+Business/publications.aspx?date $=200504$

Barrett, S. (2009). Culture shock. Retrieved November 1, 2010, from www.employeebenefits.co.uk.

Bochner, S., McLeod, B \& Lin, A. (1977). Friendship patterns of overseas students. A functional model. International Journal of Psychology, 12, 277-297

Bourne, L. (2009). Culture shock: Projects spanning cultures need more than just a good translator. Retrieved November 1, 2010, from www.pmi.org

Brown, L., \& Holloway, I. (2008). The initial stage of the international sojourn: Excitement or culture shock? British Journal of Guidance \& Counselling, 36(1), 33-49.

Church, A. (1982). Sojourner adjustment. Psychological Bulletin, 91, 540-572.

Court, D., \& King, M. (1979). Some correlates of culture shock among American tourists in Africa. International Journal of Intercultural Relations, 3, 211-225.

Cohen, E. (2007). Surviving the culture shock. Retrieved November 1, 2010, from Training And Development Online.
De Verthelyn, R. (1995) International students' spouses: Invisible sojourners in the culture shock literature. International Journal of Intercultural Relations, 19, 387-411.

Ember, C., \& Ember, M. (2004). Encyclopedia of medical anthropology: Health and illness in the world cultures. New York: Kluwer Academic/Plenum Publishers.

Furnham, A., \& Bochner, S. (1986). Culture shock. London: Methuen

Furukawa, T. (1997). Sojourner adjustment. Journal of Nervous and Mental Diseases, 185, 263-268.

Gaw, K. F. (2000). Reverse culture shock in students returning from overseas. International Journal of Intercultural Relations, 24, 83-104.

Green, R. (2006). Culture shock. Retrieved November 1, 2010, from www.foodmanufacture.co.uk.

Gunn, A. (1979). National health problems in student care. Journal of the American College Health Association, 27, 322323

Guy, B. S., \& Patton, W. E. (1996). Managing the effects of culture shock and sojourner adjustment on the expatriate industrial sales force. Industrial Marketing Management, 25, 385-393.

Hammer, M. (1992) Research mission statements and international students advisory offices. International Journal of Intercultural Relations, 16, 217-236.

Hannigan, T. (1999). Homesickness and cultural stress in the international student. In L.M. Van Tilburg \& A. Vingerhoets (Eds.), Psychological aspects of geographic movement (pp.71-81). Tilburg: Tilburg University Press.

Homans, C. (2009). Culture shock. Retrieved November 1, 2010, from www.washingtonmonthly.com.

Janca, A., \& Hetzer, J. (1992). Psychiatric morbidity of foreign students in Yugoslavia. International Journal of Social Psychiatry, 38, 287-292.

Kaye, M. (1997). Expatriate culture shock in China: A study in the Beijing hotel industry. Journal of Managerial Psychology, 12(8), 496-510.

Kennedy, A. (1999). Singaporean sojourners. Unpublished doctoral thesis. National University of Singapore.

MacPhail, B.L. (2010). Higher standards combat culture shock in medical physics. Retrieved November 1, 2010, from www.physicstoday.org

McKinlay, N., Pattison, H., \& Gross, H. (1996) An exploratory investigation of the effects of a cultural orientation programme on the psychological well-being of international university students. Higher Education 31, 379-395

McNamara, D., \& Harris, R (Eds.). (1999). Overseas students in higher education. London: Routledge

Miller, S.H. (2008). Culture shock: Causes and symptoms. International Business Research, 1(1), 26-37.

Mumford, D.B. (1998). The measurement of culture shock. Social Psychiatry and Psychiatric Epidemiology, 33, 149-154.

Nathanson, J., \& Marcuko, M. (1995). Young adolescents adjustment to the experience of relocating overseas. Relations, 19, 413-424. 
Oberg, K. (1966). Culture shock: Adjustment to new cultural environments. Practical Anthropology, 7, 177-182.

Pantelidou, S., \& Craig, T.K. (2006). Culture shock and social support: A survey in Greek migrant students. Social Psychiatry and Psychiatric Epidemiology, 41, 777-781.

Pires, G., Stanton, J., \& Ostenfeld, S. (2006). Improving expatriate adjustment and effectiveness in ethnically diverse countries: Marketing insights. Cross-cultural Management: An International Journal, 13(2), 156-170.

Pukthuanthong, K., \& Walker, T. (2007). Venture capital in China: A culture shock for Western investors. Management Decision, 45(4), 708-731.

Pyvis, D., \& Chapman, A. (2005). Culture shock and the international student 'offshore'. Journal of Research in International Education, 4(1), 23-42.

Rudmin, F. (2009). Constructs, measurements and models of acculturation and acculturative stress. International Journal of Intercultural Relations, 33, 106-123.

Sandhu, D., \& Asrabadi, B. (1994). Development of an accumulative stress scale for international students: Preliminary findings. Psychological Reports, 75, 435-448.

Sayers, J., \& Franklin, T. (2008). Culture shock! Cultural issues in a tertiary course using reflective techniques. Reflective Practice, 9(1), 79-88.

Shupe, E.I. (2007). Clashing cultures: A model of international student conflict. Journal of Cross-Cultural Psychology, 38(6), $750-771$.

Spencer-Rodgers, J., Williams, M. J., \& Peng, K. (2010). Cultural differences in expectations of change and tolerance for contradiction: A decade of empirical research. Personality and Social Psychology Review, 14(3), 296-312.

Tamura, T., \& Furnham, A. (1992). Readjustment of Japanese returning children from an overseas sojourn. Social Science and Medicine, 36, 1181-1186.

Torres, K. (2009). 'Culture shock': Black students account for their distinctiveness at an elite college. Ethnic and Racial Studies, 32(5), 883-905.

Van Heck, G., Vingerhoets, A., Voolstra, I., Gruitjers, H., \& Van Tilburg, M. (1997). Personality, temperament and home- sickness. In M. van Tilburg \& A. Vingerhoets (Eds.), Psychological aspects of geographic moves. Tilburg: Tilburg University Press.

Van Tilburg, M., \& Vingerhoets, A. (Eds.). (1997). Psychological aspects of geographic movement. Tilburg: Tilburg University Press

Ward, L. (1967). Some observations of the underlying dynamics of conflict in a foreign student. Journal of the American College Health Association, 10, 430-443.

Ward, C., \& Kennedy, A. (1993) Psychological and sociocultural adjustment during cross-cultural transients. Internal Journal of Psychology, 28, 129-147.

Ward, C., Bochner, S., \& Furnham, A. (2001). The psychology of culture shock. London: Routledge.

Ward, C., Okura, I., Kennedy, A., \& Kojima, T. (1997) The U curve on trial. International Journal of Intercultural Relations, 22, 277-291.

Willis, W. (2009). Culture shock: A new company even seems to speak a different language. Retrieved November 1, 2010 from: www.onwallstreet.com

Wikipedia. (2010). Culture shock. Retrieved November 1, 2010, fromwww.wikipedia.org.

Winkleman, M. (2003). Cultural shock and adaptation. Retrieved November 2, 2010, from www.asu.edu /clas/shesc/projects/bajaethnography/shock.htm

Wiseman, H. (1997). Far away from home: The loneliness experience of overseas students. Journal of Social and Clinical Psychology, 16, 277-298.

Xia, J. (2009). Analysis of impact of culture shock on individual psychology. International Journal of Psychological Studies, 1(2), 97-101.

Xiaoqiong, H. (2008). The culture shock that Asian students experience in immersion education. Changing English, 15(1), 101-105.

Zhou, Z., Jundal-Shape, D., Topping, K., \& Todman, J. (2008). Theoretical models of culture shock and adaptation in international students in higher education. Studies in Higher Education, 33(1), 63-75. 